\title{
Road safety in the Eastern Mediterranean Region - findings from the Global Road Safety Status Report
}

\author{
H. Soori, ${ }^{\text {S.J. Hussain }}{ }^{2}$ and J.A. Razzak ${ }^{3}$
}

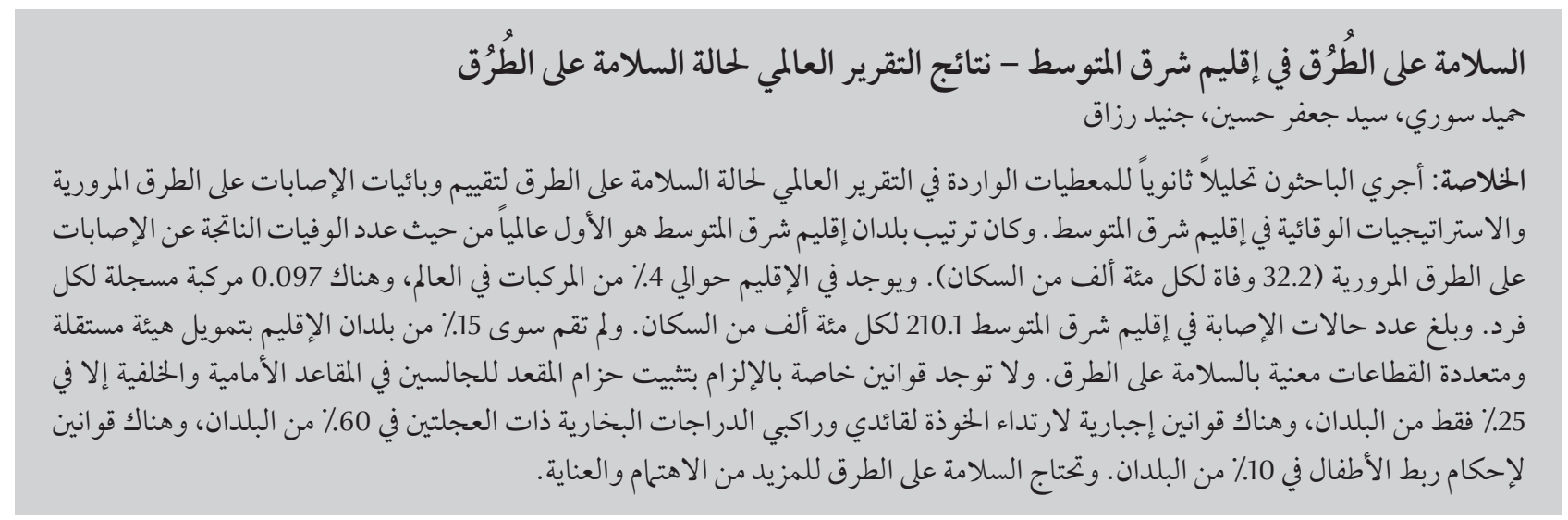

ABSTRACT A secondary data analysis using the Global Status Report on Road Safety (GSRRS) was carried out to assess the epidemiology of road traffic injuries (RTIs) and preventive strategies in the Eastern Mediterranean Region (EMR). EMR countries ranked equal first in the world for the highest number of fatalities due to RTIs (32.2 per 100000 population). The region had about 4\% of the world's vehicles with 0.097 registered vehicles per person. The number of injured cases in EMR was 210.1 per 100000 population. Only 15\% of EMR countries had a funded, independent, multisectoral body for road safety. Only 25\% had mandatory seat-belt laws for both front-seat and rear-seat passengers, 60\% had mandatory helmet laws for both drivers and passengers of motorized two-wheelers and $10 \%$ had child restraint laws. Road safety in EMR countries needs more attention and consideration.

Sécurité routière dans la Région de la Méditerranée orientale - résultats du Rapport de situation sur la sécurité routière dans le monde

RÉSUMÉ Une analyse des données secondaires extraites du Rapport de situation sur la sécurité routière dans le monde a été menée pour évaluer l'épidémiologie des traumatismes dus aux accidents de la circulation et les stratégies de prévention dans la Région de la Méditerranée orientale. Les pays de la Région sont ceux dans lesquels on constate le nombre le plus élevé au monde de décès causés par des traumatismes dus aux accidents de la circulation (32,2 pour 100000 habitants). La Région possède environ $4 \%$ des véhicules dans le monde avec 0,097 véhicule immatriculé par personne. Le nombre de cas de traumatismes en Méditerranée orientale est de 210,1 pour 100000 habitants. Seuls $15 \%$ des pays de la Région disposent d'un organisme en charge de la sécurité routière qui soit multisectoriel, indépendant et financé. Ils ne sont que $25 \%$ à avoir promulgué une loi rendant obligatoire le port de la ceinture de sécurité à l'avant comme à l'arrière des véhicules ; 60 \% des pays ont une législation sur le port obligatoire du casque pour les conducteurs comme pour les passagers de deux-roues motorisés et $10 \%$ se sont dotés d'une loi sur les dispositifs de retenue pour enfants. Davantage d'attention et de considérations doivent être accordées à la sécurité routière dans la Région de la Méditerranée orientale

'Safety Promotion and Injury Prevention Research Center, School of Public Health, Shahid Beheshti University of Medical Sciences, Tehran, Islamic Republic of Iran (Correspondence to H. Soori: hsoori@yahoo.com).

2Injury and Violence Prevention and Disability, Division of Health Promotion and Protection, World Health Organization Regional Office for the Eastern Mediterranean, Cairo, Egypt.

${ }^{3}$ Department of Emergency Medicine, the Aga Khan University, Karachi, Pakistan.

Received: 16/09/09; accepted: 31/03/10 


\section{Introduction}

Road traffic injuries (RTIs) are a serious public health problem in different regions of the world. More than 1.27 million people are killed each year due to road traffic crashes, and as many as 50 million are injured $[1,2]$. RTIs are the leading cause of death in 15-29-yearolds and result in disability for many victims. A recent study by the World Health Organization (WHO) estimated the incidence rate of fatal RTIs to be 32.2 per 100000 in the WHO Eastern Mediterranean Region (EMR), compared to 13.4 per 100000 in European Region and 18.8 per 100000 worldwide [3].

More than $90 \%$ of deaths from RTIs occur in low- and middle-income countries, which only have $48 \%$ of the world's vehicles [1]. Around 94\% of EMR residents live in low- and middleincome countries. According to the Global Status Report on Road Safety (GSRRS) about $62 \%$ of reported road traffic deaths occur in 10 countries of the world out of which 2 are in EMR. It is very important to take steps to address the global assessment of road safety, to have regular comparisons on a number of indicators between different years and countries, and present epidemiological data on RTIs for better policy-making as well as a more effective road traffic injury prevention plan [1].

The number of scientific reports on RTIs in EMR is limited compared to most of the developed countries and this paper aims to present the epidemiological pattern of RTIs in this region and compare the results for the EMR Member States and the global status of RTIs as a whole.

\section{Methods}

This is a secondary data analysis study using data from the GSRRS [1] and other available data sources in the region and international databases. EMR includes 22 countries (out of 195 member and associate member states ofWHO): Afghanistan, Bahrain, Djibouti, Egypt, Islamic Republic of Iran, Iraq, Jordan, Kuwait, Lebanon, Libyan Arab Jamahiriya, Morocco, Oman, Pakistan, Qatar, Saudi Arabia, Somalia, Sudan, Syrian Arab Republic, Tunisia, United Arab Emirates and Palestine (West Bank and Gaza). The region has about 555 million inhabitants, about $8.5 \%$ of the world population [4]. Only $6.2 \%$ of this population live in high-income countries (HIC) while the remaining live in low- and middle-income countries. In EMR, all Member States, except Djibouti and Somalia, and 1 non-member area participated in the study. These 2 countries represent $1.7 \%$ of the total population of the whole region. Details on methodology of the original study are available in GSRRS.

In summary, the work on the report began in August 2007 with the specific objectives of:

- assessing the status of road safety in all WHO Member States;

- indicating the gaps in road safety to help countries identify the key priorities for intervention;

- stimulating road safety activities at a national level.

For the original study, a self-administered questionnaire was completed by each country using a national trained coordinator, who facilitated a consensus meeting involving a multisectoral group of 8 road safety experts. Data collection began in March 2008 and was completed in September 2008.

Reported number of deaths was adjusted for 30-day definition of a road traffic death and the modelled number of deaths calculated using negative binomial regression [5] to identify outliers and determine the extent of missing data. In many countries the level of severity of an injury was recorded by different organizations; however the data on non-fatal injuries presented in this report was mainly gathered from the emergency departments of different countries.

Variables selected from GSRRS for this paper are: countries in EMR, number of deaths from RTIs, total population, number of registered vehicles, national legislations on speed limit, drink-driving law, motorcycle helmet law, seat-belt law, child restraint law, institutional framework and reported non-fatal RTIs.

Data was re-analysed using Excel 2007.

\section{Results}

Type of vehicle and trends of mortality rates were not available for all countries and so are not presented here.

\section{Population and vehicles}

Table 1 shows the total population and number of registered vehicles in 20 different countries of EMR. The total population of 20 countries recorded in this study (2007) was 545.5 million, estimated to be about $8.5 \%$ of world's population. Three countries, Egypt, Islamic Republic of Iran and Pakistan, contribute to $57 \%$ of the total population of the region (Table 1).

The total number of registered vehicles in the region was 52.74 million with $65.4 \%$ in the Islamic Republic of Iran, Saudi Arabia, Pakistan and Egypt (Table1). The total number of vehicles in the region represents about $4 \%$ of the world total. About $62.0 \%$ of the vehicles are motor cars, $19.4 \%$ buses or minibuses, $8.7 \%$ motorized 2- or 3-wheelers and $7.1 \%$ trucks. The proportion of registered vehicles per person in EMR is 0.097, while the figure for the rest of the world is 0.2 .

\section{Mortality}

In total, 175668 deaths from RTIs were reported in the region for 2007, 32.2 per 100000 population. High- 


\begin{tabular}{|c|c|c|c|c|}
\hline \multirow[t]{2}{*}{ Country } & \multicolumn{2}{|c|}{ Population } & \multicolumn{2}{|c|}{ Total registered vehicles } \\
\hline & No. & $\%$ & No. & $\%$ \\
\hline Afghanistan & 27145275 & 4.98 & 731607 & 1.41 \\
\hline Bahrain & 752648 & 0.14 & 382977 & 0.74 \\
\hline Egypt & 75497913 & 13.84 & 4300000 & 8.28 \\
\hline Iran (Islamic Republic of) & 71208384 & 13.05 & 17000000 & 32.72 \\
\hline Iraq & 28993374 & 5.31 & 2242269 & 4.32 \\
\hline Jordan & 5924245 & 1.09 & 841933 & 1.62 \\
\hline Kuwait & 2851144 & 0.52 & 1364790 & 2.63 \\
\hline Lebanon & 4099115 & 0.75 & 1400000 & 2.69 \\
\hline Libyan Arab Jamahiriya & 6160483 & 1.13 & 1826533 & 3.52 \\
\hline Morocco & 31224137 & 5.72 & 2284060 & 4.39 \\
\hline Oman & 2595133 & 0.48 & 629670 & 1.21 \\
\hline Pakistan & 163902405 & 30.04 & 5287152 & 10.17 \\
\hline Qatar & 840635 & 0.15 & 605699 & 1.17 \\
\hline Saudi Arabia & 24734533 & 4.53 & 7398600 & 14.24 \\
\hline Sudan & 38560488 & 7.07 & 1200000 & 2.31 \\
\hline Syrian Arab Republic & 19928516 & 3.65 & 1389346 & 2.67 \\
\hline Tunisia & 10327285 & 1.89 & 1244918 & 2.39 \\
\hline United Arab Emirates & 4380439 & 0.80 & 1754420 & 3.38 \\
\hline West Bank and Gaza & $4018000^{a}$ & 0.74 & 78609 & 0.15 \\
\hline Yemen & 22389169 & 6.03 & 777734 & 1.50 \\
\hline Total & 545533321 & 100 & 52740317 & 100 \\
\hline
\end{tabular}

${ }^{a} 2007$ data not available; latest available used from http://data.un.org/.

income and middle-income countries of EMR have the highest death rate from RTIs in the world. These death rates were more than 3 and 2 times greater than the lowest rates in other high-income and middle-income countries of the world respectively (Table 2).
The RTI fatality rate in EMR is $6.4 \%$ of total global deaths from RTIs [1]. The Islamic Republic of Iran has the highest number of deaths from RTIs and is responsible for $14.5 \%$ of total deaths from all causes in the region. However, the highest rates of fatal RTIs (per 100000 population) are for Egypt (41.6\%), Libyan Arab Jamahiriya (40.5\%) and Afghanistan (39.0\%) (Table 3). Fatal RTIs per 10000 vehicles was 33.8. Table 3 gives more details of the actual and modelled number of deaths and modelled rates (per 100000 population) in 20 countries of the region.

\begin{tabular}{lcccc}
\hline $\begin{array}{l}\text { Table } 2 \text { Modelled road traffic injury fatality rates (per } \mathbf{1 0 0} \\
\text { and income group }\end{array}$ & High-income & Middle-income & Low-income & Total \\
\hline WHO Region & 28.5 & 35.8 & 27.5 & 32.2 \\
Eastern Mediterranean & - & 32.2 & 32.3 & 32.2 \\
African $^{b}$ & - & 16.7 & 16.5 & 16.6 \\
South-East Asian $^{\text {b }}$ & 13.4 & 17.3 & - & 15.8 \\
Americas $^{c}$ & 7.2 & 16.9 & 15.6 & 15.6 \\
Western Pacific $_{\text {European }}$ & 7.9 & 19.3 & 12.2 & 13.4 \\
Global & 10.3 & 19.5 & 21.5 & 18.8 \\
\hline
\end{tabular}

a30-day definition

${ }^{b}$ No high-income countries

cNo low-income countries

Source: Global status report on road safety [1]. 


\begin{tabular}{|c|c|c|c|}
\hline Country & $\begin{array}{c}\text { Reported number of } \\
\text { deaths } s^{\mathrm{a}}\end{array}$ & $\begin{array}{l}\text { Modelled number of } \\
\text { deaths }^{b}\end{array}$ & $\begin{array}{l}\text { Estimated road traffic death rate } \\
\text { per } 100000 \text { population }{ }^{b}\end{array}$ \\
\hline Afghanistan & 1779 & 10593 & 39.0 \\
\hline Bahrain & 91 & 91 & 12.1 \\
\hline Egypt & 15983 & 31439 & 41.6 \\
\hline Iran (Islamic Republic of) & 22918 & 25491 & 35.8 \\
\hline Iraq & 1932 & 11059 & 38.1 \\
\hline Jordan & 992 & 2027 & 34.2 \\
\hline Kuwait & 482 & 482 & 16.9 \\
\hline Lebanon & 536 & 1170 & 28.5 \\
\hline Libyan Arab Jamahiriya & 2138 & 2497 & 40.5 \\
\hline Morocco & 3838 & 8850 & 28.3 \\
\hline Oman & 798 & 553 & 21.3 \\
\hline Pakistan & 7234 & 41494 & 25.3 \\
\hline Qatar & 199 & 199 & 23.7 \\
\hline Saudi Arabia & 6358 & 7166 & 29.0 \\
\hline Sudan & 2227 & 13362 & 34.7 \\
\hline Syrian Arab Republic & 3663 & 6552 & 32.9 \\
\hline Tunisia & 1497 & 3568 & 34.5 \\
\hline United Arab Emirates & 1056 & 1626 & 37.1 \\
\hline West Bank and Gaza & 188 & 896 & 22.3 \\
\hline Yemen & 3003 & 6553 & 29.3 \\
\hline Total & 76912 & 175668 & 32.2 \\
\hline
\end{tabular}

${ }^{a}$ Adjusted for 30-day definition of a road traffic death.

${ }^{b}$ Modelled using negative binomial regression (http://www.who.int/violence_injury_prevention/road_safety_status/methodology/en/index.html for detailed methodology).

\section{Morbidity}

The number of people injured in the region in 2007 was 1145958 which is 210.1 per 100000 population. This equates to 220.5 per 10000 vehicles in the region. The Islamic Republic of Iran with more than 962.8 per 100000 population has the highest rate of nonfatal RTIs in the region. The highest rates of non-fatal injuries from RTIs per 10000 registered vehicles are in Qatar, Pakistan and Iraq with 17.4, 24.6, 33.3 respectively. Table 4 gives details of non-fatal RTI rates per 100000 population and per 10000 vehicles in participating countries of EMR.

\section{Enforcement of laws and legislations}

Table 5 shows the presence of certain important laws and legislations on road safety in different countries of EMR.

Few countries in EMR (15\%) have a funded, independent, multisectoral body for road safety. In EMR, $90 \%$ of the countries had a seat-belt law but only $25 \%$ had mandatory seat-belt laws for both front-seat and rear-seat passengers. The majority of countries (85\%) have some form of helmet law for 2-wheelers vehicles but only about $60 \%$ have mandatory helmet laws for both rider and passenger. Only 10\% of EMR countries have child restraint laws.

National speed limits in urban areas for vehicles in 20 countries of the region ranged from $50 \mathrm{~km} / \mathrm{h}$ in many countries to $120 \mathrm{~km} / \mathrm{h}$. Oman $(120$ $\mathrm{km} / \mathrm{h}$ ), Iraq, Qatar and Lebanon (100 $\mathrm{km} / \mathrm{h}$ ) have the highest speed limits in urban areas.
Blood alcohol concentration over $0 \mathrm{~g} / \mathrm{dL}$ is illegal for the general population for most of the countries in the region while it is $0.10 \mathrm{~g} / \mathrm{dL}$ in the United Arab Emirates. There was no difference in blood alcohol concentration levels for the general population, young/novice drivers and professional/commercial drivers in all countries. Except in Morocco, all other countries have national drinkdriving laws and in some countries alcohol consumption is prohibited. The methods used for enforcing drink-driving laws are mostly through measurement of blood alcohol concentration and by random breath testing by police check-points in 8 countries (Afghanistan, Islamic Republic of Iran, Kuwait, Lebanon, Oman, Pakistan, Tunisia and United Arab Emirates). 


\begin{tabular}{|c|c|c|c|}
\hline Country & Number of reported cases & $\begin{array}{c}\text { Rate per } 100000 \\
\text { population }\end{array}$ & Rate per 10000 vehicles \\
\hline Afghanistan & 16980 & 62.6 & 232.1 \\
\hline Bahrain & 3415 & 453.7 & 89.2 \\
\hline Egypt & 154000 & 204.0 & 358.1 \\
\hline Iran (Islamic Republic) & 685611 & 962.8 & 403.3 \\
\hline Iraq & 7467 & 25.8 & 33.3 \\
\hline Jordan & 17969 & 303.3 & 213.4 \\
\hline Kuwait & 8584 & 301.1 & 62.9 \\
\hline Lebanon & 6266 & 152.9 & 44.8 \\
\hline Libyan Arab Jamahiriya & 9524 & 154.6 & 52.1 \\
\hline Morocco & 89264 & 285.9 & 390.8 \\
\hline Oman & 8531 & 328.7 & 135.5 \\
\hline Pakistan & 12990 & 7.9 & 24.6 \\
\hline Qatar & 1053 & 125.3 & 17.4 \\
\hline Saudi Arabia & 36025 & 145.6 & 48.7 \\
\hline Sudan & 21329 & 55.3 & 177.7 \\
\hline Syrian Arab Republic & 16145 & 81.0 & 116.2 \\
\hline Tunisia & 14559 & 141.0 & 116.9 \\
\hline United Arab Emirates & 11155 & 254.7 & 63.6 \\
\hline West Bank and Gaza & 5838 & 145.3 & 742.7 \\
\hline Yemen & 19253 & 86.0 & 247.6 \\
\hline Total & 1145958 & 210.1 & 220.5 \\
\hline
\end{tabular}

\section{Discussion}

In 2007 in EMR, there were 32.2 RTI deaths per 100000 population. While this was the same as the African region, it was much higher than the 13.4 per 100000 in the European region. Indeed, only 2 countries of EMR (Bahrain and Kuwait) had lower death rates from RTIs than the world estimate of 18.8 per 100000 . EMR ranked second after the African region for fatal RTIs per vehicle; 87.3 per 10 000 vehicles for the African region versus 33.8 for EMR. The figure is 3.2 per 10000 vehicles for the European region and 9.3 per 10000 vehicles for the world.

The number of people injured in the region in 2007 was 1145958 (210.1 per 100000 population) which is lower than the 269.3 per 100000 reported in the European region.

Few countries in EMR (15\%) had a funded, independent, multisectoral body for road safety while this figure was about $74 \%$ in the European region. In addition, only $25 \%$ of EMR countries had mandatory seat-belt laws for both front-seat and rear-seat passengers compared to about $92 \%$ in the European region, and only $60 \%$ had mandatory helmet laws for both rider and passenger compared to $98 \%$ in the European region. In fact, only the Islamic Republic of Iran, Sudan and Tunisia meet the recognized helmet standards. Only $10 \%$ of EMR countries had laws in place on restraint of children in cars compared to $86 \%$ in European region.

This study shows that EMR has one of the worst road safety situations in the world. The fatality rate per 100 000 population ranked first equal (with the African region), While injuries per 100000 population were lower, the validity and reliability of the data on non-fatal RTIs derived from secondary data set is open to question [6]. In many countries, non-fatal injuries from RTIs are recorded by police at the site of the crash, whereas in some less severe injuries are either not recorded and/or a standardized scoring method for injury severity is not used. Thus, there may in fact be an under-reporting of non-fatal injuries. As a result, data on non-fatal injuries on RTIs are not comparable between different countries of the region and rest of the world.

Injuries apart, the high fatality rate compared with Europe raises the question of response to road traffic crashes, the facilities available to deal with RTIs, access to care and the quality of medical care received. In middle- and lowincome countries, adequate capacity may be limited.

Our study shows that some driving safety laws are in place but they are not as far-reaching as those in the European region. In addition, laws need to be enforced but our study could not determine how well the current laws were being implemented.

This is the first report on road safety in EMR that shows an overall picture 


\begin{tabular}{|c|c|c|c|c|c|}
\hline Country & $\begin{array}{l}\text { National drink- } \\
\text { driving law }\end{array}$ & $\begin{array}{l}\text { Random breath testing } \\
\text { or police check-points }\end{array}$ & Helmet law & Seat-belt law & $\begin{array}{c}\text { Child } \\
\text { restraint law }\end{array}$ \\
\hline Afghanistan & $Y_{e s}{ }^{a}$ & Yes & No & No & No \\
\hline Bahrain & $Y_{e s}{ }^{a}$ & No & Yes & Yes & No \\
\hline Egypt & Yes & No & Yes & Yes & No \\
\hline Iran (Islamic Republic) & $Y_{e s^{a}}$ & Yes & Yes & Yes & No \\
\hline Iraq & Yes & No & No & Yes & No \\
\hline Jordan & Yes & - & Yes & Yes & No \\
\hline Kuwait & $Y_{e s}{ }^{a}$ & Yes & Yes & Yes & No \\
\hline Lebanon & Yes & Yes & Yes & Yes & No \\
\hline Libyan Arab Jamahiriya & $Y s^{\mathrm{a}}$ & No & Yes & Yes & No \\
\hline Morocco & No & - & Yes & Yes & No \\
\hline Oman & Yes & Yes & Yes & Yes & No \\
\hline Pakistan & $Y_{e s}{ }^{a}$ & Yes & Yes & Yes & No \\
\hline Qatar & Yes & No & Yes & Yes & No \\
\hline Saudi Arabia & Yes & No & Yes & Yes & Yes \\
\hline Sudan & $Y_{e s}{ }^{a}$ & No & Yes & Yes & No \\
\hline Syria & Yes & No & Yes & Yes & No \\
\hline Tunisia & Yes & Yes & Yes & Yes & No \\
\hline United Arab Emirates & Yes & Yes & Yes & Yes & No \\
\hline West Bank and Gaza & Yes & No & Yes & Yes & Yes \\
\hline Yemen & $Y_{e s}{ }^{a}$ & - & No & No & No \\
\hline
\end{tabular}

${ }^{a}$ Alcohol is prohibited [1].

of RTIs in 20 member countries of the region. Published studies from different EMR countries are limited. A comprehensive review in Safetylit [7] showed that there were only 138 papers on RTIs from member countries of EMR published in international scientific journals from 1966 to September 2008. More than $71 \%$ of these papers were from Saudi Arabia (31), Islamic Republic of Iran (23), Pakistan (26) and United Arab Emirates (18); there were no published studies on RTIs for 4 member countries.

Findings from this report showsome similarities and some differences from the literature published from studies in the region. Most studies in different countries of the region show RTIs as a major cause of death in those countries [8-17]. For example, a higher frequency of RTIs in the Islamic Republic of Iran, Pakistan and Saudi Arabia has been reported $[6,10,16]$. However, the scope of the problem of high rates of RTIs per 100000 population in Egypt, Libyan Arab Jamahiriya and Afghanistan has not been well documented.

Although 12 of the countries in the region reported that they had a lead agency on road safety, only 3 countries that had a funded national strategy with measurable targets and so the data available were limited to basic road safety management.

Interventions, particularly the enforcement of laws and legislation and obligatory rules for use of seat-belts by drivers and car occupants, wearing of helmet by motorcyclists and educational programmes, can be effective in RTI prevention and in lowering the RTI rates $[18,19]$. Such interventions should be strictly implemented in different parts of the region. In addition, more reliable evidence is needed to determine the scope of different types of injuries and to evaluate the interventions already implemented. While some countries in the region have taken steps towards addressing road safety, additional efforts are needed. Some studies show that despite increasing numbers of cars, there is a lack of significant environmental modifications for road and vehicle safety promotion [1].

In conclusion, RTIs are a serious problem in EMR with one of the highest fatality rates in the world. Researchers in the region are encouraged to study the scope of the problem, risk factors, interventions and evaluation of road traffic injuries in their own countries as well as the region. Stronger leadership from the lead agency and adequate resources and support for infrastructure are required and that the health sector should take a more active role in RTI prevention. In addition, policy-makers need to endorse proven interventions and their implementation. 


\section{References}

1. Global status report on road safety: time for action. Geneva, World Health Organization, 2009.

2. Peden $\mathrm{M}$ et al. World report on road traffic injury prevention. Geneva, World Health Organization, 2004.

3. The global burden of disease: 2004 update. Geneva, World Health Organization, 2008.

4. World health statistics 2008. Geneva, World Health Organization, 2008 (http://www.who.int/whosis/en/, accessed 18 August 2011)

5. World Health Organization. Violence and Injury Prevention and Disability (VIP) [webpage] (http://www.who.int/violence_injury_prevention/road_safety_status/methodology/ en/index.html, accessed 18 August 2011).

6. Razzak JA, Laflamme L. Limitations of secondary data sets for road traffic injury epidemiology. Prehospital and Disaster Medicine, 2005, 9(3):355-360.

7. Safetylit. Safety Literature Service [website] (http://www. safetylit.org/, accessed 18 August 2011).

8. Al-Madani $\mathrm{H}, \mathrm{Al}-\mathrm{Janahi} \mathrm{A}$. Personal exposure risk factors in pedestrian accidents in Bahrain. Safety Science, 2006 44(4):335-347.

9. Sakr K, Farag IA, Zeitoun IM. Review of 509 mandibular fractures treated at the University Hospital, Alexandria, Egypt. British Journal of Oral and Maxillofacial Surgery, 2006, 44(2):107-111.

10. Akbari ME, Naghavi M, Soori H. Epidemiology of deaths from injuries in the Islamic Republic of Iran. Eastern Mediterranean Health Journal, 2006, 12(3-4):382-390.
11. Adeloye A, Al-Kuoka N, Ssembatya-Lule GC. Pattern of acute head injuries in Kuwait. East African Medical Journal, 1996, 73(4):253-258.

12. Razzak JA et al. Injuries among children in Karachi, Pakistan-what, where and how. Public Health, 2004, 118(2):114-120.

13. Ghaffar A, Hyder AA, Masud TI. The burden of road traffic injuries in developing countries: the 1st national injury survey of Pakistan. Public Health, 2004, 118(3):211-217.

14. Bener A et al. The impact of four-wheel drives on traffic disability and deaths compared to passenger cars. Journal of the College of Physicians and Surgeons, Pakistan, 2006, 16(4):257-260.

15. Bener A. The neglected epidemic: road traffic accidents in a developing country, State of Qatar. International Journal of Injury Control and Safety Promotion, 2005, 12(1):45-47.

16. Ansari $\mathrm{S}$ et al. Causes and effects of road traffic accidents in Saudi Arabia. Public Health, 2000, 114(1):37-39.

17. El-Sadig $M$ et al. Road traffic accidents in the United Arab Emirates: trends of morbidity and mortality during 1977-1998. ACcident Analysis \& Prevention, 2002, 34(4):465-476.

18. Soori $\mathrm{H}$ et al. Road traffic injuries in Iran: the role of interventions implemented by traffic police. Traffic Injury Prevention, 2009, 10:4,375-378.

19. Liu BC et al. Helmets for preventing injury in motorcycle riders. The Cochrane Database of Systematic Reviews, 2004, Issue 4. 